Article

\title{
Morphologies Tuning of Polypyrrole and Thermoelectric Properties of Polypyrrole Nanowire/Graphene Composites
}

\author{
Yong Du ${ }^{1, * \mathbb{D}}$, Hao Niu ${ }^{1}$, Jun $\mathrm{Li}^{1}$, Yunchen Dou ${ }^{1}$, Shirley Z. Shen ${ }^{2}$, Runping Jia ${ }^{1}$ and \\ Jiayue $\mathrm{Xu}{ }^{1, *}$ \\ 1 School of Materials Science and Engineering, Shanghai Institute of Technology, 100 Haiquan Road, \\ Shanghai 201418, China; nh954779551@163.com (H.N.); 156081106@mail.sit.edu.cn (J.L.); \\ yunchendou@sit.edu.cn (Y.D.); Jiarp@sit.edu.cn (R.J.) \\ 2 CSIRO Manufacturing, Private Bag 10, Clayton South, VIC 3169, Australia; shirley.shen@csiro.au \\ * $\quad$ Correspondence: ydu@sit.edu.cn (Y.D.); xujiayue@sit.edu.cn (J.X.); Tel.: +86-182-1701-7450 (Y.D.)
}

Received: 11 August 2018; Accepted: 29 September 2018; Published: 13 October 2018

\begin{abstract}
Polypyrrole (PPy) with different morphologies (e.g., particles, nanotubes, and nanowires) were successfully prepared by adding or without adding different kinds of surfactants through a chemical oxidative polymerization method, respectively. The results show that the morphologies of PPy can be effectively controlled and have a significantly effects on their thermoelectric properties. The PPy nanowires exhibit the highest electrical conductivity and Seebeck coefficient among the various PPy morphologies, such as particles, nanotubes, and nanowires, so PPy nanowires were chosen to prepare PPy nanowire/graphene thermoelectric composites via a soft template polymerization method using cetyltrimethyl ammonium bromide as the template. Both electrical conductivity and Seebeck coefficient of the PPy nanowire/graphene composites increased as the content of graphene increases from 0 to $20 \mathrm{wt} \%$, and as the measured temperature increases from $300 \mathrm{~K}$ to $380 \mathrm{~K}$, which leds to the same trend for the power factor. A highest power factor of $1.01 \mu \mathrm{Wm}^{-1} \mathrm{~K}^{-2}$ at $\sim 380 \mathrm{~K}$ was obtained for the PPy nanowire/graphene composites with $20 \mathrm{wt} \%$ PPy nanowire, which is about 3.3 times higher than that of the pure PPy nanowire.
\end{abstract}

Keywords: polypyrrole nanowire; graphene; composite; thermoelectric

\section{Introduction}

Since the discovery of the Seebeck effect in 1821 by German scientist Thomas Johann Seebeck [1], most of researchers have focused on inorganic thermoelectric (TE) materials, such as $\mathrm{Bi}-\mathrm{Te}-, \mathrm{Pb}-\mathrm{Te}-$, and Si-Ge-based alloys, and this phenomenon has continued until the begining of the 21st century. More and more attention has been paid to conducing polymer TE materials and their corresponding TE nanocomposite materials [2-5].

Polypyrrole (PPy), one kind of conducting polymers, has many outstanding features, such as, low density, low thermal conductivity, and easy fabrication [3,6]; therefore, PPy has a great potential for TE materials individually or as a matrix for nanocomposites. A PPy film was prepared by an electrochemical method, and a power factor $\left(P F=S^{2} \sigma\right.$, where $S$ is Seebeck coefficient and $\sigma$ is electrical conductivity) of $3.9 \mu \mathrm{Wm}^{-1} \mathrm{~K}^{-2}$ (ZT value of $6.8 \times 10^{-3}$ ) was achieved at $300 \mathrm{~K}$ [6]. A lamellar PPy doped with $\beta$-naphthalene sulfonic acid was fabricated, and a power factor of about $0.4 \mu \mathrm{Wm}^{-1} \mathrm{~K}^{-2}$ (ZT value of $6.2 \times 10^{-3}$ ) was obtained with the molar ratio of monomer pyrrole to $\beta$-naphthalene sulfonic acid being 1.0:0.45 at $300 \mathrm{~K}$ [7]. In addition, a multi-walled carbon nanotube (MWCNT)/PPy composite was fabricated by an in situ polymerization method, and a power factor of $2.2 \mu \mathrm{Wm}^{-1} \mathrm{~K}^{-2}$ was achieved 
for the composite with $68 \mathrm{wt} \%$ MWCNT at room temperature (RT) [8]. A single-walled carbon nanotube (SWCNT)/PPy nanocomposite was made by an in situ polymerization method, and a power factor of $5.46 \mu \mathrm{Wm}^{-1} \mathrm{~K}^{-2}$ was obtained at $398 \mathrm{~K}$ for the nanocomposite with $40 \mathrm{wt} \%$ SWCNT [9]. A reduced graphene oxide ( $\mathrm{rGO}$ ) nanosheet/PPy composite was prepared by a template-directed in situ polymerization, and a power factor of $3.01 \mu \mathrm{Wm}^{-1} \mathrm{~K}^{-2}$ was achieved with the $\mathrm{rGO} / \mathrm{Py}$ mass ration of 2:1 at RT [10].

Poly(3,4-ethylenedioxythiophene) (PEDOT), one of the most studied conducing polymers, shows a potential application prospect in TE [11]. The morphologies of PEDOT have significantly effects on its TE properties, as both the Seebeck coefficient and electrical conductivity of PEDOT were reported increased with the morphologies of globular nanoparticles, nanotubes, and nanofibers [12]. Wu et al. [13] reported that the p-toluenesulfonic acid (p-TSA) doped polyaniline (PANi) nanowires showed higher Seebeck coefficient and lower thermal conductivity than that of p-TSA-doped nanorods. However, most of the research on PPy were mainly focused on PPy particles (PPy-PTs) and PPy-PT-based TE nanocomposites. The research on the 1-D PPy nanostructures, e.g., PPy nanotubes (PPy-NTs), PPy nanowires (PPy-NWs), and their corresponding TE composites is very limited, although some progress have been reported [14,15]. A polypyrrole nanotube (PPy-NT) film was prepared, and a power factor of $0.31 \mu \mathrm{Wm}^{-1} \mathrm{~K}^{-2}\left(\mathrm{ZT}\right.$ value of $\left.5.71 \times 10^{-4}\right)$ at $310 \mathrm{~K}$ was obtained [14]. A PPy-NWs was prepared and a power factor of $22.6 \times 10^{-3} \mu \mathrm{Wm}^{-1} \mathrm{~K}^{-2}$ was achieved [15]. It is a significant need to investigate the morphologies of PPy (e.g., PPy-PTs, PPy-NTs, and PPy-NWs) on the TE properties of themselves and their corresponding composites.

Graphene, is commonly used as a filler for the conducting polymer matrix to prepare conducting polymer based nanocomposites [16]. For example, PPy/graphene nanocomposite can be used in many areas [17-21], such as, lithium batteries [19], supercapacitors [20], electrode materials [21], etc. Furthermore, as a kind of fillers, graphene can also improve the TE properties of the conducting polymers, due to its high electrical conductivity [22,23]. For example, the graphene/poly $(3,4-$ ethylenedioxythiophene) (PEDOT) composites [23] and graphene/polyaniline (PANI) composites [22] were reported. However, so far, to the best of our knowledge, no systematic research about the influence of morphologies of PPy (e.g., PPy-PTs, PPy-NTs and PPy-NWs) on their TE properties and PPy-NW/graphene composites has been reported. In this work, PPy with different morphologies (PPy-PTs, PPy-NTs and PPy-NWs) were successfully prepared by adding or without adding different kinds of surfactants through a chemical oxidative polymerization method, respectively. The effects of the morphologies of PPy-PTs, PPy-NTs, and PPy-NWs on their TE properties have been investigated, and the results show that PPy-NWs has the highest power factor. Therefore, PPy-NW/graphene TE composites have been prepared via a soft template polymerization method using cetyltrimethyl ammonium bromide as the template. The compositions, morphologies, and TE properties of the $\mathrm{PPy}-\mathrm{NW} /$ graphene composites with different contents of graphene have also been investigated.

\section{Experimental}

\subsection{Materials}

Pyrrole monomer (chemical grade) was purchased from Sigma-Aldrich (Shanghai, China). Methyl orange (reagent grade) and cetyltrimethyl ammonium bromide (CTAB, reagent grade) were purchased from Adamas Reagent Co., Ltd. (Shanghai, China). $\mathrm{FeCl}_{3} \cdot 6 \mathrm{H}_{2} \mathrm{O}$ (analytical reagent), and absolute ethanol (reagent grade) were purchased from Sinopharm Chemical Reagent Co., Ltd. (Shanghai, China). Ammonium peroxydisulfate (APS) (oxidant) was purchased from Shanghai Titanchem Co., Ltd. (Shanghai, China) Graphene was purchased from Nanjing XFNANO Materials Tech Co., Ltd. (Nanjing, China). All the materials were used without further treatment or purification.

\subsection{Preparation of the PPy Particles}

Typical synthetic process of PPy particles was as follow [24]: $0.55 \mathrm{~mL}$ of pyrrole monomer was dissolved in $100 \mathrm{~mL}$ of deionized water (Solution A). $8.65 \mathrm{~g}$ of $\mathrm{FeCl}_{3} \cdot 6 \mathrm{H}_{2} \mathrm{O}$ was dissolved in $100 \mathrm{~mL}$ of 
deionized water (Solution B), which was added to Solution A to initiate the polymerization. The mixed solution was constantly stirred at $50 \mathrm{rpm}$ for $8 \mathrm{~h}$ at RT. The products was washed with deionized water and absolute ethanol successively for three times, and then dried at $60^{\circ} \mathrm{C}$ for $12 \mathrm{~h}$.

\subsection{Preparation of the PPy Nanotubes}

Typical synthetic process of PPy nanotubes was as follow [25]: $0.49 \mathrm{~g}$ methyl orange (MO) and $0.56 \mathrm{~mL}$ pyrrole monomer was dissolved in $150 \mathrm{~mL}$ of deionized water (Solution A). Then $8.72 \mathrm{~g}$ $\mathrm{FeCl}_{3} \cdot 6 \mathrm{H}_{2} \mathrm{O}$ dissolved in $100 \mathrm{~mL}$ of deionized water (Solution $\mathrm{B}$ ), was then added to Solution $\mathrm{A}$ and constantly stirred for $8 \mathrm{~h}$ at RT. The products was washed with deionized water and absolute ethanol successively for three times, and then dried at $60^{\circ} \mathrm{C}$ for $12 \mathrm{~h}$.

\subsection{Preparation of the PPy-NWs and PPy-NW/Graphene Nanocomposites}

Typical synthetic process of PPy-NWs was: $0.66 \mathrm{~g}$ CTAB was dissolved in $200 \mathrm{~mL}$ of $0.5 \mathrm{~mol} / \mathrm{L}$ hydrochloride $(\mathrm{HCl})$ (Solution A), a designed mount of graphene (5 wt \%, $10 \mathrm{wt} \%, 15 \mathrm{wt} \%$, and $20 \mathrm{wt} \%$ ) was added into Solution A, stirred for $30 \mathrm{~min}$ and then ultrasoniced for $2 \mathrm{~h} .1 .6 \mathrm{~mL}$ pyrrole monomer was added into the above solution to form Solution B. $1.23 \mathrm{~g}$ APS dissolved in $200 \mathrm{~mL}$ of $0.5 \mathrm{~mol} / \mathrm{L} \mathrm{HCl}$ (Solution C), was then added to Solution B and constantly stirred for $8 \mathrm{~h}$ in an ice bath. The products was washed with deionized water and absolute ethanol successively for three times, and then dried at $60^{\circ} \mathrm{C}$ for $8 \mathrm{~h}$. For a comparison, PPy-NWs were also prepared using the same procedure but without graphene. Figure 1 illustrates the formation procedure of PPy-PTs, PPy-NTs, and PPy-NWs. Figure 2 illustrates the procedure for the preparation of PPy-NW/graphene composites.

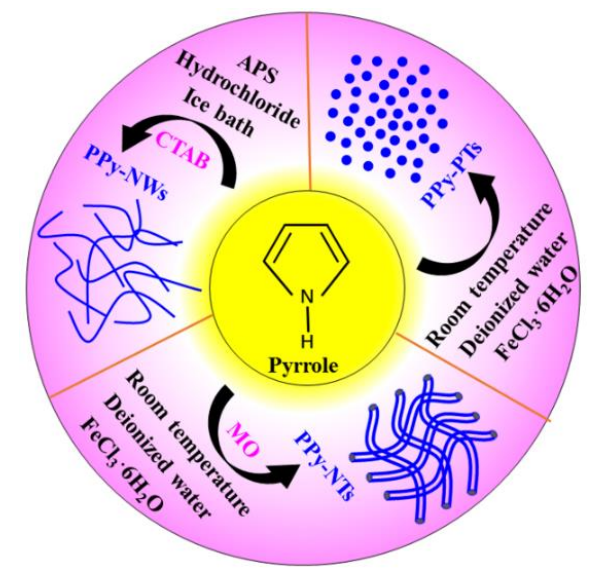

Figure 1. Schematic illustration of the formation procedure of PPy-PTs, PPy-NTs, and PPy-NWs.

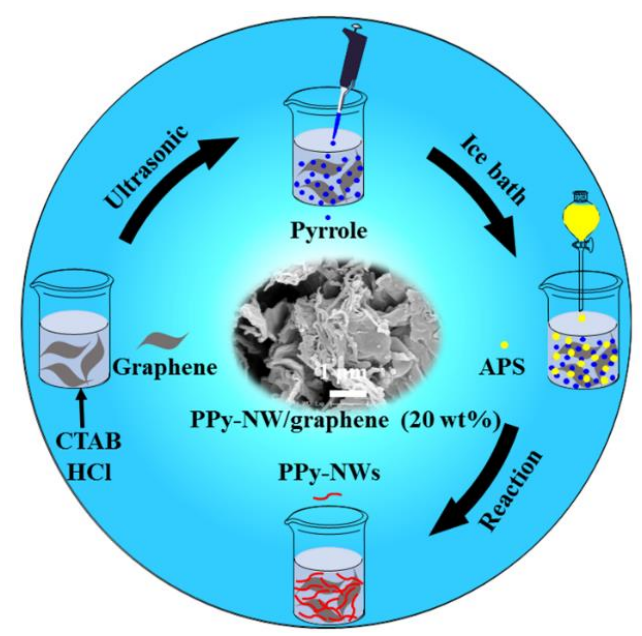

Figure 2. Schematic illustration of the procedure for preparation of PPy-NW/graphene composites. 


\subsection{Characterizations}

The phase composition and morphology of the samples were characterized using X-Ray photoelectron spectroscopic (XPS, PHI 5000 VersaProbe, ULVAC-PHI, Chigasaki, Japan), scanning electron microscopy (SEM, Philips XL 30 FEG, Philips, Eindhoven, The Netherlands), and transmission electron microscopy (TEM, CM200-FEG, Philips, Eindhoven, The Netherlands), respectively. The electrical conductivity and Seebeck coefficient were measured simultaneously in a vacuum atmosphere from 300 to $380 \mathrm{~K}$ on an MRS-3L thin-film thermoelectric test system (Wuhan Giant Instrument Technology Co., Ltd., Wuhan, China).

\section{Results and Discussion}

Figure 3 shows the SEM and TEM images of the PPy-PTs, PPy-NTs, and PPy-NWs, respectively. When $\mathrm{FeCl}_{3} \cdot 6 \mathrm{H}_{2} \mathrm{O}$ was used as an oxidant without a surfactant, PPy-PTs were obtained and agglomerated together to form an analogous spherical morphology (Figure 3a,b), which agrees with the Reference [9]. When $\mathrm{FeCl}_{3} \cdot 6 \mathrm{H}_{2} \mathrm{O}$ and $\mathrm{MO}$ were used as an oxidant and a surfactant, respectively, PPy-NTs were achieved (Figure 3c,d), mainly due to pyrrole monomer was polymerized on the surface of the 1D templates [25-27], which were formed due to MO change from its salt form (high water solubility) into acid form (poor water solubility). When APS was used as an oxidant and CTAB was used as a surfactant, PPy-NWs were formed (Figure 3e,f), mainly due to hydrophobic pyrrole monomer entered the micelles formed by CTAB with the cationic hydrophilic heads towards the outside, and after APS was added into the solution, a lamellar mesostructual (CTA) ${ }_{2} \mathrm{~S}_{2} \mathrm{O}_{8}$ soft template was formed, and then pyrrole monomer was polymerized into PPy-NWs at the inward of the soft templates $[15,28,29]$. From the SEM and TEM images of PPy-NTs and PPy-NWs, we can see that the diameter of the prepared PPy-NTs and PPy-NWs are $\sim 70 \mathrm{~nm}$ to $150 \mathrm{~nm}$ and $\sim 30 \mathrm{~nm}$ to $60 \mathrm{~nm}$, respectively, while the lengths of PPy-NTs and PPy-NWs are in the $\mu \mathrm{m}$-range (Figure $3 \mathrm{c}-\mathrm{f}$ ). Based on the above-mentioned experimental results, we can conclude that the morphologies of PPy (e.g., PPy-PTs, PPy-NTs, and PPy-NWs) can be effectively controlled and tuned via adjusting the experimental conditions, such as adding or without adding different kinds of surfactants.

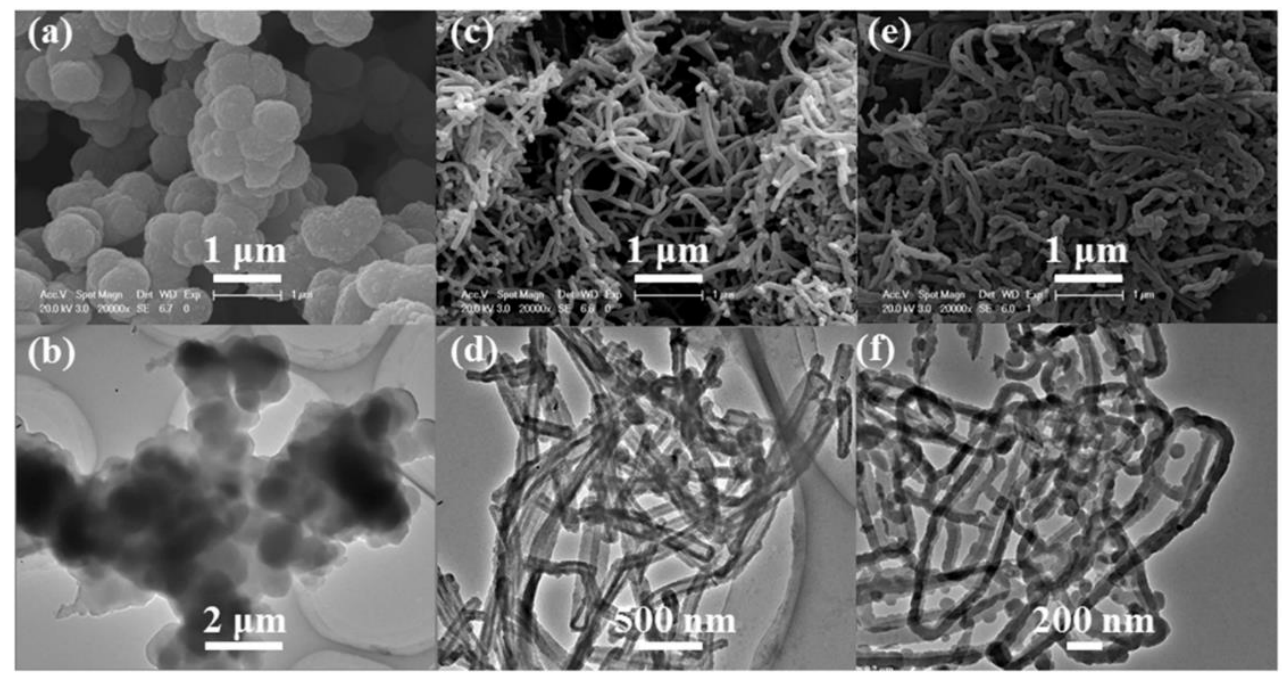

Figure 3. SEM images of (a) PPy-PTs, (c) PPy-NTs, and (e) PPy-NWs. TEM images of (b) PPy-PTs, (d) PPy-NTs, and (f) PPy-NWs.

Figure 4 shows the electrical conductivity, Seebeck coefficient, and power factor of the PPy-PTs, PPy-NTs, and PPy-NWs. As the measured temperature increased from 300 to $380 \mathrm{~K}$, both electrical conductivity and Seebeck coefficient of the PPy-PTs, PPy-NTs, and PPy-NWs increased, which leads to a same trend for the power factor. The electrical conductivity and Seebeck coefficient of PPy-NWs were much higher than those of PPy-PTs and PPy-NTs in the whole temperature ranges. This phenomenon 
was similar to that of PEDOT with different morphologies reported in Reference [12]. Considering the higher power factor of PPy-NWs, compared to PPy-PTs or PPy-NTs, hereafter, PPy-NW/graphene composites have been prepared and the influence of graphene contents on the morphologies and TE properties of the composites have been investigated and reported below.
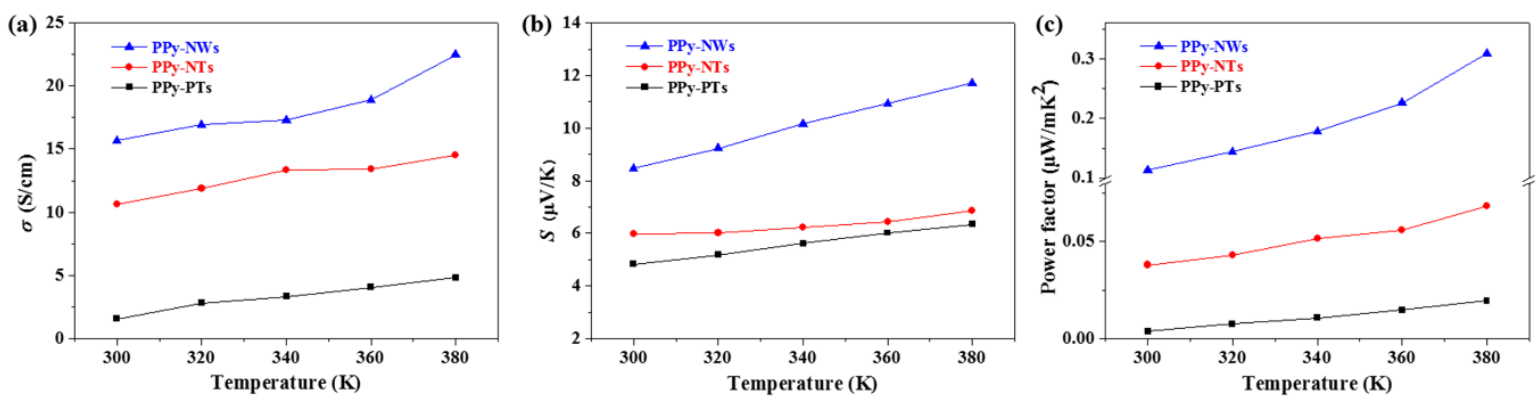

Figure 4. Electrical conductivity (a), Seebeck coefficient (b), and power factor (c), of the PPy-PTs, PPy-NTs, and PPy-NWs.

Figure 5 shows the SEM images of PPy-NWs, graphene and PPy-NW/graphene composites with different contents of graphene from 5 to $20 \mathrm{wt} \%$, and TEM images of graphene and PPy-NW/graphene composites with $20 \mathrm{wt} \%$ graphene. The surfaces of PPy-NW/graphene composites (Figure $5 \mathrm{c}-\mathrm{f}$ ) were much rougher when compared to the pure graphene (Figure 5b), due to the surfaces of graphene were covered by PPy-NWs. It can be also clearly seen that as the content of graphene increased from 5 to $20 \mathrm{wt} \%$ (Figure $5 \mathrm{c}-\mathrm{f}$ ), the loading of PPy-NWs on the graphene surfaces decreased, mainly because of the surface areas of graphene increased in the nanocomposites. PPy-NWs have not only been uniformly coated on the surface of graphene, but also acted as bridges between different graphene (Figure $5 c-f, h$ ). The formation mechanism of PPy-NW/graphene composites is mainly due to the electrostatic attractions and $\pi-\pi$ interactions between the graphene and hydrophobic pyrrole monomer [28,30], which made pyrrole monomer adsorbed on the surfaces of graphene. After APS was added into the solution, a lamellar mesostructual (CTA $)_{2} \mathrm{~S}_{2} \mathrm{O}_{8}$ soft template was formed, and then pyrrole monomer was polymerized into PPy-NWs at the inward of the soft templates and therefore adsorbed on the surfaces of graphene $[15,28,29]$. PPy-PTs and PPy-NTs mainly contain C, O, N, and Cl $\left(\mathrm{Cl}\right.$ came from $\mathrm{FeCl}_{3} \cdot 6 \mathrm{H}_{2} \mathrm{O}$ ), while PPy-NWs and PPy-NW/graphene composites (Figure 6) have $\mathrm{C}, \mathrm{O}$, $\mathrm{N}$, and S. It indicates PPy-NWs have been coated on the surface of graphene. Note that $\mathrm{S}$ comes from APS, which is agree with the Reference [31].

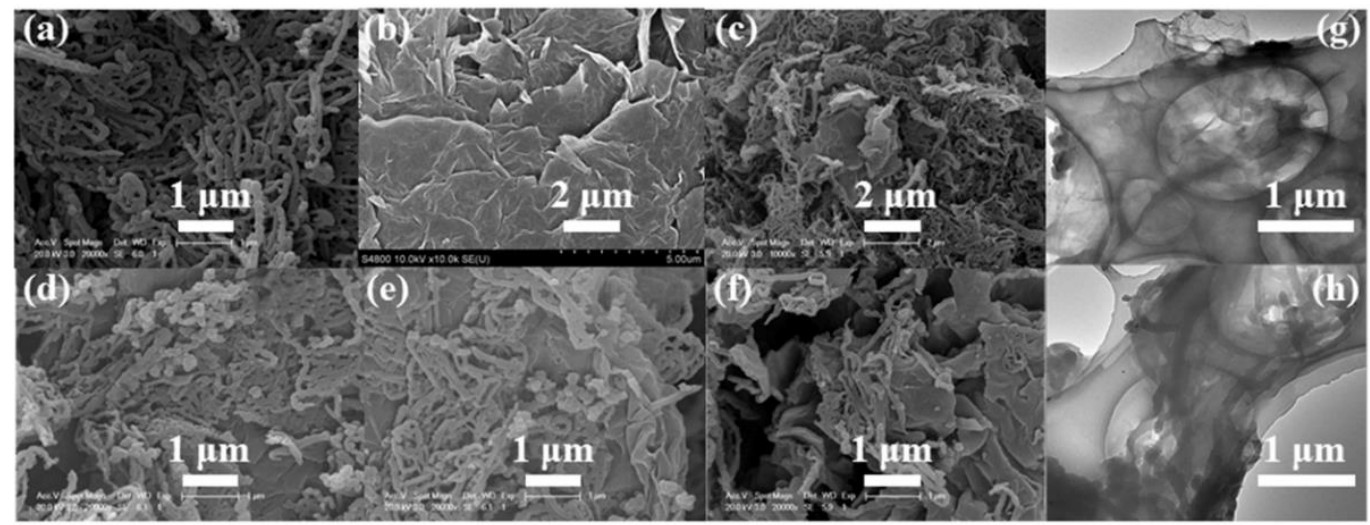

Figure 5. SEM images of (a) PPy-NWs, (b) graphene, PPy-NW/graphene composites with, (c) 5 wt \%, (d) $10 \mathrm{wt} \%$, (e) $15 \mathrm{wt} \%$, and (f) $20 \mathrm{wt} \%$ of graphene. TEM images of (g) graphene and (h) PPy-NW/ graphene composites with $20 \mathrm{wt} \%$ of graphene. 


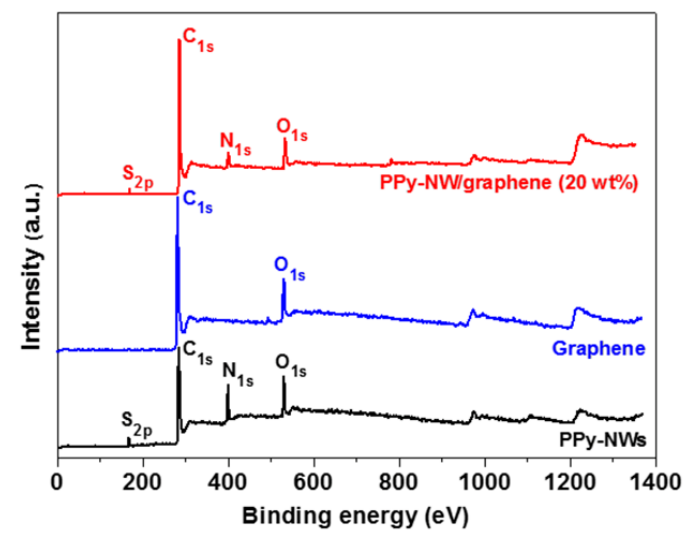

Figure 6. XPS spectra of wide region spectroscopy of graphene, PPy-NWs, and PPy-NW/graphene composites.

The electrical conductivity, Seebeck coefficient, and power factor of the PPy-NWs, and PPy-NW/ graphene composites with different contents of graphene are shown in Figure 7 . The electrical conductivity of the PPy-NW/graphene composites have increased as the content of graphene increasing from 0 to $20 \mathrm{wt} \%$, e.g., from $15.7 \mathrm{~S} / \mathrm{cm}$ for the pure PPy-NWs to $32.3 \mathrm{~S} / \mathrm{cm}$ for the nanocomposites with $20 \mathrm{wt} \%$ graphene at $300 \mathrm{~K}$. The reason for this phenomenon is mainly because of the following two aspects: (1) graphene has a much higher electrical conductivity than that of the PPy-NWs; and (2) PPy-NWs are not only coated on the surfaces of graphene, but also acted as bridges between graphene in the nanocomposites (see Figure 5), which benefits for the carriers' transportation. As the content of graphene increases from 0 to $20 \mathrm{wt} \%$, the Seebeck coefficient of the nanocomposites increases from 8.5 to $13.7 \mu \mathrm{V} / \mathrm{K}$ at $300 \mathrm{~K}$, probably due to more interfaces have been introduced in the nanocomposites. The power factor of the nanocomposites increases from $0.1 \mu \mathrm{Wm}^{-1} \mathrm{~K}^{-2}$ to $0.6 \mu \mathrm{Wm}^{-1} \mathrm{~K}^{-2}$ with the contents of graphene increasing from 0 to $20 \mathrm{wt} \%$ at $300 \mathrm{~K}$. It is mainly because of the simultaneous increase in conductivity and Seebeck coefficient of the nanocomposites. The electrical conductivity and Seebeck coefficient of the PPy-NW/graphene nanocomposites also increase slightly as the temperature increases from 300 to $380 \mathrm{~K}$. E.g., the electrical conductivity and Seebeck coefficient increases from $32.3 \mathrm{~S} / \mathrm{cm}(300 \mathrm{~K})$ to $36.9 \mathrm{~S} / \mathrm{cm}(380 \mathrm{~K})$, and from $13.7 \mu \mathrm{V} / \mathrm{K}(300 \mathrm{~K})$ to $16.5 \mu \mathrm{V} / \mathrm{K}(380 \mathrm{~K})$, respectively, for the composites with $20 \mathrm{wt} \%$ of graphene. As a result, the power factor of the nanocomposites also increases as the temperature increases from 300 to $380 \mathrm{~K}$, and a highest power factor of $1.01 \mu \mathrm{Wm}^{-1} \mathrm{~K}^{-2}$ at $380 \mathrm{~K}$ has been obtained for the PPy-NW/graphene composites with $20 \mathrm{wt} \%$ of graphene. It is about 3.3 times higher than that pure PPy-NWs $\left(0.31 \mu \mathrm{Wm}^{-1} \mathrm{~K}^{-2}\right.$ at $\left.380 \mathrm{~K}\right)$. However, this value is still lower than that of a MWCNT/PPy composites $\left(2.2 \mu \mathrm{Wm}^{-1} \mathrm{~K}^{-2}\right.$ at RT with $68 \mathrm{wt} \%$ MWCNT) [8], a SWCNT/PPy composites (5.46 $\mu \mathrm{Wm}^{-1} \mathrm{~K}^{-2}$ at $398 \mathrm{~K}$ with $40 \mathrm{wt} \%$ SWCNT) [9], or a rGO nanosheet/PPy composites $\left(3.01 \mu \mathrm{Wm}^{-1} \mathrm{~K}^{-2}\right.$ with $66.7 \mathrm{wt} \% \mathrm{rGO}$ at RT) [10]. It is mainly due to the contents of graphene in the studied nanocomposites $(20 \mathrm{wt} \%)$ is much lower than that of MWCNT (68 wt \%), SWCNT (40 wt \%), or rGO (66.7 wt \%) in the reported nanocomposites [8-10].
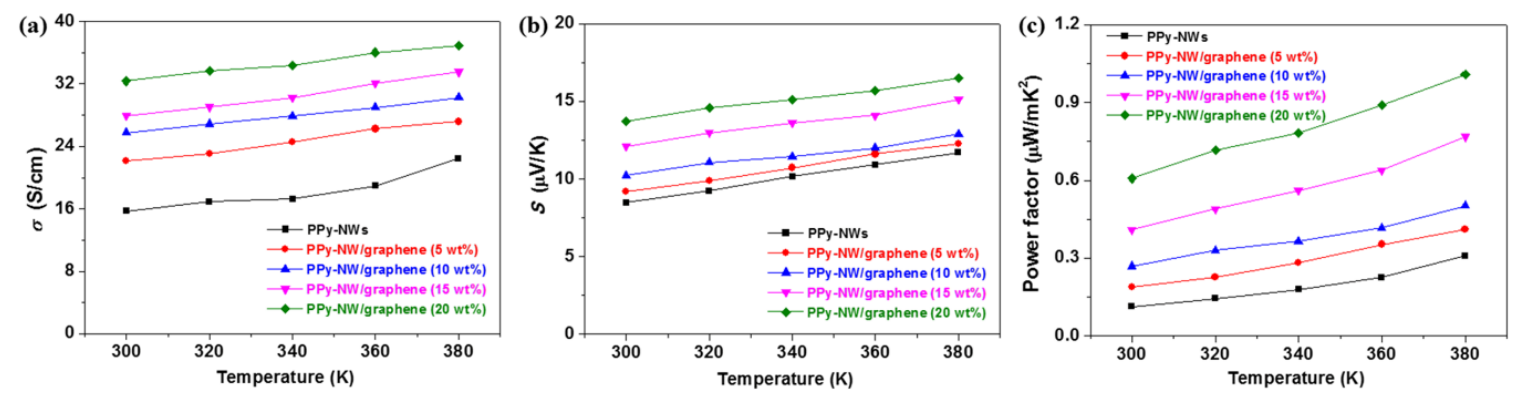

Figure 7. Electrical conductivity (a), Seebeck coefficient (b), and power factor (c), of PPy-NW/graphene composites with different content of graphene. 


\section{Conclusions}

PPy with different morphologies (i.e., PPy-PTs, PPy-NTs, and PPy-NWs) have been successfully prepared and their TE properties have also been investigated. The results show that the PPy-NWs have the highest TE properties among all the morphologies of PPy. PPy-NW/graphene thermoelectric composites have been prepared via a soft template polymerization method. Both electrical conductivity and Seebeck of the PPy-NW/graphene composites increases along the contents of graphene from 0 to $20 \mathrm{wt} \%$, or as the temperature increases from $300 \mathrm{~K}$ to $380 \mathrm{~K}$. A highest power factor of $1.01 \mu \mathrm{Wm}^{-1} \mathrm{~K}^{-2}$ at $380 \mathrm{~K}$ was obtained for the PPy-NW/graphene composites with $20 \mathrm{wt} \%$ of graphene. It was about 3.3 times higher than that of pure PPy-NWs.

Author Contributions: Y.D. designed the experiments, performed data analysis, wrote and revised the manuscript; H.N. and J.L. performed the experiments, data analysis, and wrote the manuscript; Y.D. performed part of data analysis; S.Z.S. revised the manuscript; R.J. and J.X. provided additional intellectual insight. Y.D. and J.X. conceived the overall project.

Funding: This work has been supported by the National Natural Science Foundation of China (61504081, 61611530550), the Program for Professor of Special Appointment (Young Eastern Scholar Program) at Shanghai Institutions of Higher Learning (QD2015039), the Shanghai Innovation action plan project (17090503600, 15520503400), and Shanghai Education Development Foundation and Shanghai Science and Technology Achievement Transformation Foundation (LM201678).

Conflicts of Interest: The authors declare no conflict of interest.

\section{References}

1. Seebeck, T.J. Magnetische Polarisation der Metalle und erze Durch Temperatur-Differenz; Abh. Akad. Wiss.: Berlin, Germany, 1822; pp. 289-346.

2. Du, Y.; Xu, J.Y.; Paul, B.; Eklund, P. Flexible thermoelectric materials and devices. Appl. Mater. Today 2018, 12, 366-388. [CrossRef]

3. Du, Y.; Shen, S.Z.; Cai, K.F.; Casey, P.S. Research progress on polymer-inorganic thermoelectric nanocomposite materials. Prog. Polym. Sci. 2012, 37, 820-841. [CrossRef]

4. Zhang, Q.; Sun, Y.M.; Xu, W.; Zhu, D.B. Organic thermoelectric materials: Emerging green energy materials converting heat to electricity directly and efficiently. Adv. Mater. 2014, 26, 6829-6851. [CrossRef] [PubMed]

5. Gao, C.Y.; Chen, G.M. Conducting polymer/carbon particle thermoelectric composites: Emerging green energy materials. Compos. Sci. Technol. 2016, 124, 52-70. [CrossRef]

6. Culebras, M.; Uriol, B.; Gomez, C.M.; Cantarero, A. Controlling the thermoelectric properties of polymers: Application to PEDOT and polypyrrole. Phys. Chem. Chem. Phys. 2015, 17, 15140-15145. [CrossRef] [PubMed]

7. Tang, X.X.; Liu, T.X.; Li, H.; Yang, D.W.; Chen, L.J.; Tang, X.F. Notably enhanced thermoelectric properties of lamellar polypyrrole by doping with $\beta$-naphthalene sulfonic acid. RSC Adv. 2017, 7, 20192-20200. [CrossRef]

8. Song, H.J.; Cai, K.F.; Wang, J.; Shen, S. Influence of polymerization method on the thermoelectric properties of multi-walled carbon nanotubes/polypyrrole composites. Synth. Met. 2016, 211, 58-65. [CrossRef]

9. Du, Y.; Xu, J.Y.; Lin, T. Single-Walled Carbon Nanotube/Polypyrrole Thermoelectric Composite Materials; IOP Conference Series: Earth and Environmental Science; IOP Publishing: Bristol, UK, 2017; Volume 108, p. 022040.

10. Han, S.B.; Zhai, W.T.; Chen, G.M.; Wang, X. Morphology and thermoelectric properties of graphene nanosheets enwrapped with polypyrrole. RSC Adv. 2014, 4, 29281-29285. [CrossRef]

11. Kim, G.H.; Shao, L.; Zhang, K.; Pipe, K.P. Engineered doping of organic semiconductors for enhanced thermoelectric efficiency. Nat. Mater. 2013, 12, 719-723. [CrossRef] [PubMed]

12. Hu, X.C.; Chen, G.M.; Wang, X.; Wang, H.F. Tuning thermoelectric performance by nanostructure evolution of a conducting polymer. J. Mater. Chem. A 2015, 3, 20896-20902. [CrossRef]

13. Wu, J.S.; Sun, Y.M.; Xu, W.; Zhang, Q.C. Investigating thermoelectric properties of doped polyaniline nanowires. Synth. Met. 2014, 189, 177-182. [CrossRef]

14. Wu, J.S.; Sun, Y.M.; Pei, W.B.; Ling, H.; Xu, W.; Zhang, Q.C. Polypyrrole nanotube film for flexible thermoelectric application. Synth. Met. 2014, 196, 173-177. [CrossRef] 
15. Liang, L.R.; Chen, G.M.; Guo, C.Y. Polypyrrole nanostructures and their thermoelectric performance. Mater. Chem. Front. 2017, 1, 380-386. [CrossRef]

16. Xie, J.; Zhao, C.E.; Lin, Z.Q.; Gu, P.Y.; Zhang, Q.C. Nanostructured conjugated polymers for energy-related applications beyond solar cells. Chem. Asian J. 2016, 11, 1489-1511. [CrossRef] [PubMed]

17. Bose, S.; Kuila, T.; Uddin, M.E.; Kim, N.H.; Lau, A.K.T.; Lee, J.H. In-situ synthesis and characterization of electrically conductive polypyrrole/graphene nanocomposites. Polymer 2010, 51, 5921-5928. [CrossRef]

18. Zhao, Y.C.; Lu, Z.; Tian, J.N.; Nie, S.L.; Zhen, N. Enhanced electrocatalytic oxidation of methanol on $\mathrm{Pd}$ /polypyrrole-graphene in alkaline medium. Electrochim. Acta 2011, 56, 1967-1972. [CrossRef]

19. Yang, Y.; Wang, C.Y.; Yue, B.B.; Gambhir, S.; Too, C.O.; Wallace, G.G. Electrochemically synthesized polypyrrole/graphene composite film for lithium batteries. Adv. Energy Mater. 2012, 2, 266-272. [CrossRef]

20. Oliveira, H.P.D.; Sydlik, S.A.; Swager, T.M. Supercapacitors from free-standing polypyrrole/graphene nanocomposites. J. Phys. Chem. C 2013, 117, 10270-10276. [CrossRef]

21. Gao, Y.S.; Xu, J.K.; Lu, L.M.; Wu, L.P.; Zhang, K.X.; Nie, T.; Zhu, X.F.; Wu, Y. Overoxidized polypyrrole/ graphene nanocomposite with good electrochemical performance as novel electrode material for the detection of adenine and guanine. Biosens. Bioelectron. 2014, 62, 261-267. [CrossRef] [PubMed]

22. Du, Y.; Shen, S.Z.; Yang, W.D.; Donelson, R.; Cai, K.F.; Casey, P.S. Simultaneous increase in conductivity and Seebeck coefficient in a polyaniline/graphene nanosheets thermoelectric nanocomposite. Synth. Met. 2012, 161, 2688-2692. [CrossRef]

23. Kim, G.H.; Hwang, D.H.; Woo, S.I. Thermoelectric properties of nanocomposite thin films prepared with poly(3,4-ethylenedioxythiophene) poly(styrenesulfonate) and graphene. Phys. Chem. Chem. Phys. 2012, 14, 3530-3536. [CrossRef] [PubMed]

24. Li, J.; Du, Y.; Jia, R.P.; Xu, J.Y.; Shen, S.Z. Thermoelectric properties of flexible PEDOT: PSS/polypyrrole/paper nanocomposite Films. Materials 2017, 10, 780. [CrossRef] [PubMed]

25. Li, J.; Du, Y.; Jia, R.P.; Xu, J.Y.; Shen, S.Z. Flexible thermoelectric composite films of polypyrrole nanotubes coated paper. Coatings 2017, 7, 211. [CrossRef]

26. Sapurina, I.; Li, Y.; Alekseeva, E.; Bober, P.; Trchová, M.; Morávková, Z.; Stejskal, J. Polypyrrole nanotubes: The tuning of morphology and conductivity. Polymer 2017, 113, 247-258. [CrossRef]

27. Kopecká, J.; Kopecký, D.; Vrňata, M.; Fitl, P.; Stejskal, J.; Trchová, M.; Bober, P.; Morávková, Z.; Prokeš, J.; Sapurina, I. Polypyrrole nanotubes: Mechanism of formation. RSC Adv. 2014, 4, 1551-1558. [CrossRef]

28. Zhang, Z.; Chen, G.M.; Wang, H.F.; Zhai, W.T. Enhanced thermoelectric property by the construction of a nanocomposite 3D interconnected architecture consisting of graphene nanolayers sandwiched by polypyrrole nanowires. J. Mater. Chem. C 2015, 3, 1649-1654. [CrossRef]

29. Zhang, X.T.; Zhang, J.; Liu, Z.F.; Robinson, C. Inorganic/organic mesostructure directed synthesis of wire/ribbon-like polypyrrole nanostructures. Chem. Commun. 2004, 1852-1853. [CrossRef] [PubMed]

30. Xu, C.H.; Sun, J.; Gao, L. Synthesis of novel hierarchical graphene/polypyrrole nanosheet composites and their superior electrochemical performance. J. Mater. Chem. 2011, 21, 11253-11258. [CrossRef]

31. Zhang, X.T.; Zhang, J.; Song, W.H.; Liu, Z.F. Controllable synthesis of conducting polypyrrole nanostructures. J. Phys. Chem. B 2006, 110, 1158-1165. [CrossRef] [PubMed]

(C) 2018 by the authors. Licensee MDPI, Basel, Switzerland. This article is an open access article distributed under the terms and conditions of the Creative Commons Attribution (CC BY) license (http:// creativecommons.org/licenses/by/4.0/). 